\title{
A RARE CASE OF SCHWANNOMA OF TRIGEMINAL NERVE WITH INTRAORBITAL EXTENSION
}

Shruti S. Patil ${ }^{1}$, Ananth ${ }^{2}$, Atahar Sultana ${ }^{3}$

\section{HOW TO CITE THIS ARTICLE:}

Shruti S. Patil, Ananth, Atahar Sultana. "A Rare Case of Schwannoma of Trigeminal Nerve with Intraorbital Extension". Journal of Evolution of Medical and Dental Sciences 2015; Vol. 4, Issue 80, October 05; Page: 14094-14097, DOI: $10.14260 /$ jemds/2015/2003

ABSTRACT: Schwannomas, also known as neurilemmomas, are benign peripheral nerve sheath tumors. Trigeminal schwannomas are rare intracranial tumors. Here, we report a 35-year-old female presenting with an axial proptosis of right eyeball with right-sided III, IV and VI cranial nerve palsy. Her best corrected visual acuity in the right eye was perception of light absent and in the left eye was 20/20. MRI scan revealed a large right-sided heterogeneous, extra-axial middle cranial fossa mass that extended to the intraconal space of right orbit. A diagnosis of intracranial trigeminal nerve schwannoma with right orbital extension was made. Successful surgical excision of the mass with preservation of the surrounding tissues and orbital exenteration was done. Post-operative period was uneventful.

INTRODUCTION: We present a rare case of schwnnoma of the right trigeminal nerve (V1 segment) of 40 year female patient presented with pain and watering in the right eye redness and forward proptosis. CT brain reveals intraconal mixed density lesion with solid cystic component causing proptosis and widening of optic canal extending to middle cranial fossa possibly optic nerve glioma. MRI of brain reveals intensely heterogeneously enhancing orbital neoplasm with intra and extra conal component with areas of haemorrhage and necrosis. The lesion seen to encase right cavernous sinus and right internal carotid artery and displacing the cavernous sinus medially and pituitary laterally possibly optic nerve sheath tumour -schwannoma or optic nerve glioma. However HPR reveals schwannoma of the V1segment of right trigeminal nerve.

Schwannomas are usually benign (WHO GRADE I) tumors arising from the schwann cells in the axon myelin sheaths.[1] Trigeminal schwannomas are rare intracranial tumors, accounting for $0.8 \%$ to $8 \%$ of intracranial schwannomas. Trigeminal schwannomas are much less common than acoustic neuroma.[2] This benign tumor grow larger and spread into extracranial compartments through the foramina in the skull.[3] The variable location and presentation of this tumor makes the diagnosis difficult. The diagnosis is usually confirmed by histopathological examination. Here we present a rare case of benign intracranial trigeminal schwannoma arising from right parasellar region extending to intraconal space of the right orbit which was managed successfully by surgery.

CASE REPORT: A 40-year-old female presented with a pain and watering in the right eye since 10 years associated with redness since 1 year. She also complained of forward protrusion of right eyeball for past 10 years. General physical examination was unremarkable. On ocular examination best corrected vision was normal. Ophthalmometry showed $4 \mathrm{~mm}$ proptosis in the right eye. The size of proptosis did not vary with posture or with valsalva maneuver.

CT of PNS and ORBIT revealed mixed density intraconal lesion with solid cystic component noted in the right orbit with kinking and displacement of the optic nerve, widening of optic canal downward displacement of the globe. The lesion is extending into the right middle cranial fossa. On 


\section{CASE REPORT}

contrast study lesion shows mild enhancement of the solid part. Rest of the brain parenchyma was normal.

MRI images of brain and orbit demonstrated a large well encapsulated heterogeneously hyper intense T2 Wt mass lesion noted in the right orbit causing proptosis, having intra and extra conal component which appears to enlarge superior orbital fissure/optic canal leading to encase and displace right cavernous sinus and pituitary gland. There was encasement of the right internal carotid artery. The mass lesion appears to displace intraorbital optic nerve superomedially resulting in moderate atrophy of the same. Post contrast study reveals heterogeneous intense enhancement of the lesion with few non-enhancing areas suggestive of necrosis. On SWI sequence areas of intratumoral blooming noted suggestive of haemorrhage.

On the basis of the MRI and CT features and the location of the mass, a suggestive diagnosis of optic nerve sheath tumor schwannoma, optic nerve glioma was given. The patient was operated and HPR reports confirmed it to be schwannoma of the trigeminal nerve (V1segment).

Biopsy Report: microscopic sections show fragments of neoplasm formed by wavy spindle cells arranged in hypo and hypercellular areas. Verrocay bodies are seen. Thick walled blood vessels are seen. Negative for evidence of malignancy.

Impression: Schwannoma of ophthalmic division of trigeminal nerve.

DISCUSSION: Trigeminal schwannomas are slow-growing encapsulated tumors composed of differentiated schwann cells of sensory root. It can originate in any section of the trigeminal nerve. Trigeminal schwannomas are classified in four types according to the locations: Middle fossa type (type A), posterior fossa root type (type B) where the tumor is in front of brainstem, dumbbellshaped type with both middle and posterior fossa components (type C) and extracranial tumor with intracranial extension (type D).[4,5] Yoshida and Kawase classified extracranial schwannomas into infratemporal, orbital and pterygopalatine fossa components. ${ }^{[6]}$ The schwannoma of orbit accounts for $1-4 \%$ of all orbital neoplasm. ${ }^{[7]}$ The tumor has no significant sex predilection and age of presentation varies from 6 months to 72 years. Because of the subtle nature of symptoms and neglect of early symptoms, majority of the tumors achieve a large size before their diagnosis is made. The variable origin and location of this tumor causes combination of signs and symptoms in the patients. ${ }^{[8]}$ Paresthesia or numbness in more than one division of the nerve are common complaints of patients rather than severe neuralgic pain. Wasting of the temporalis and pterygoid muscles are usually diagnostic for the disorder. The corneal reflex is often diminished or absent.

Larger size of the tumor can involve the adjoining cranial nerves in the cavernous sinus. The larger tumor is responsible for relatively uncommon symptoms of increased intracranial pressure and ophthalmoscopically demonstrated papilledema. Radiologically the erosion of the petrous apex and erosion of foramen ovale, rotendum, superior orbital fissure and displacement of the internal carotid artery are characteristic and have diagnostic value. About $24 \%$ of orbital schwannomas have been reported to originate from the first division of the trigeminal nerve. The displacement of the eyeball is related to the site and extent of the tumor mass. The orbital tumor can present with proptosis, diplopia, limitation of eye ball movement and neuropathy. In our case most of those features were present. Most schwannomas require early treatment as they grow progressively. The growth of the tumor may compress the optic nerve to produce optic disc edema or optic atrophy. The tumor should be removed earliest to prevent optic nerve compression. ${ }^{[9]}$ This benign tumor may 
undergo malignant change. Trigeminal schwannomas are removed by relatively small and straightforward exposures with minimum brain handling. Surgical excision of the tumor is the treatment of choice and radiation therapy is an alternative treatment in some cases. Incomplete excisions may lead to recurrences.

In our case, the tumor was a trigeminal schwannoma affecting the first division of the trigeminal nerve (Ophthalmic division). There were also III, IV and VI cranial nerve palsy of right side causing restricted extraocular movements in the right eye. She had optic atrophy due to compression of the optic nerve by the tumor. A schwannoma though rare should be considered as a differential diagnosis of a unilateral slow growing orbital mass particularly in an adult and early intervention is needed to prevent development of vision-threatening complications.

\section{REFERENCES:}

1. Goel A, Muzumdar D, Raman C. Trigeminal neuroma: Analysis of surgical experience with 73 cases. Neurosurgery. 2003; 52:783-90. [PubMed].

2. Atlas S. Magnetic Resonance Imaging of the Brain and Spine. 2nd ed. Philadelphia: Lippincott Raven; 1996. pp. 781-6.

3. MacNally SP, Rutherford SA, Ramsden RT, Evans DG, King AT. Trigeminal schwannomas. Br J Neurosurg. 2008; 22:729-38. [PubMed].

4. Jefferson G. The trigeminal schwannomas with some remarks on malignant invasion of the gasserian ganglion. Clin Neurosurg. 1955; 1:11-54. [PubMed].

5. Lesoin F, Rousseaux M, Villette L, Autricque A, Dhellemmes P, Pellerin P, et al. Neurinomas of the trigeminal nerve. Acta Neurochir (Wien) 1986; 82:118-22. [PubMed].

6. Yoshida K, Kawase T. Trigeminal neurinomas extending into multiple fossae: Surgical methods and review of the literature. J Neurosurg. 1999; 91:202-11. [PubMed].

7. Volpe NJ, Gausas RE. Optic nerve and orbital tumors. Neurosurg Clin N Am. 1999; 1 0:699. [PubMed].

8. Rootman J, Goldberg C, Robertson W. Primary orbital schwannomas. Br J Ophthalmol. 1982; 66:194-204. [PMC free article] [PubMed].

9. Konrad EA, Thiel HJ. Schwannoma of the orbit. Ophthalmologica. 1984; 188:118-27. [PubMed].

Fig. 1: C T BRAIN: Shows mixed density intraconal lesion with solid cystic component with extention into the right middle cranial fossa.

Fig. 2: T1 Wt Image: Shows mildly hyper intense lesion with hypo intensities within the lesion with intra and extra conal component.
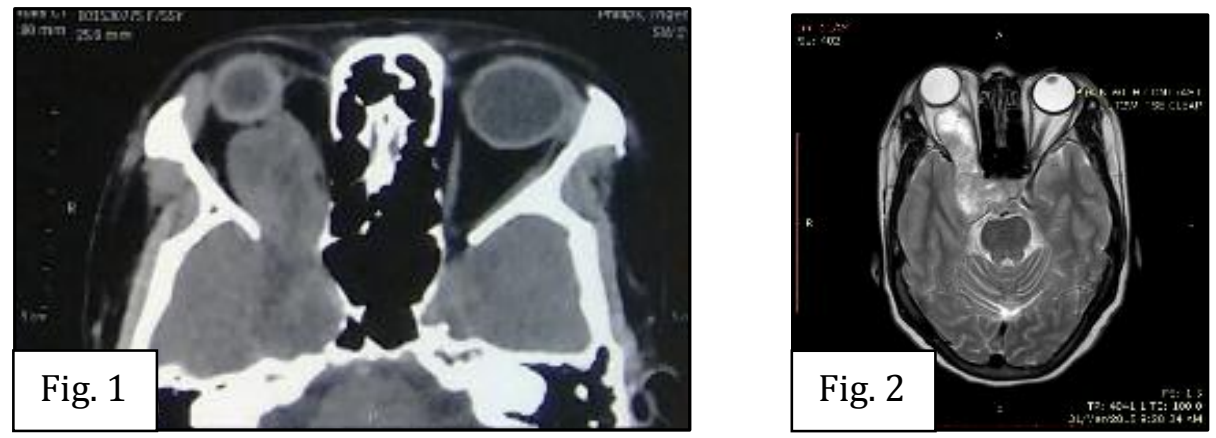


\section{CASE REPORT}

Fig. 3 \& 4: T2 Wt Image axial and sagittal view: Shows heterogeneously hyper intense mass lesion with intra and extra conal component and mass effect over cavernous sinus.

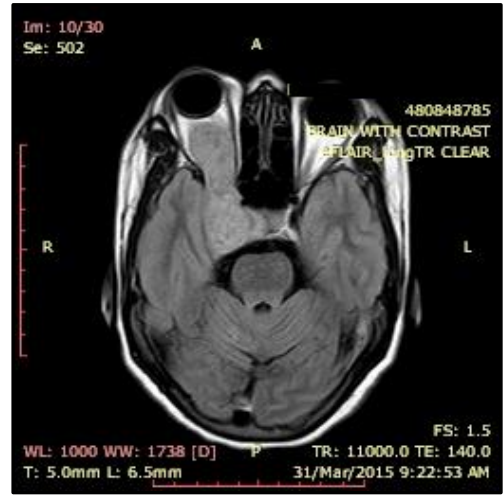

Fig. 3

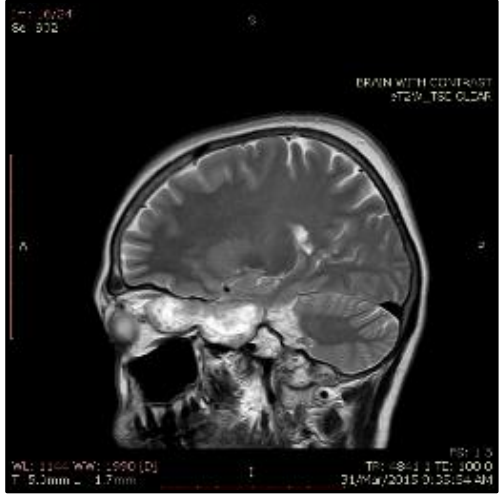

Fig. 4

FIG 5 and 6: T1 wt contrast images sagittal and axial view: Shows heterogeneous intense enhancement of the lesion with few non-enhancing areas suggestive of necrosis.

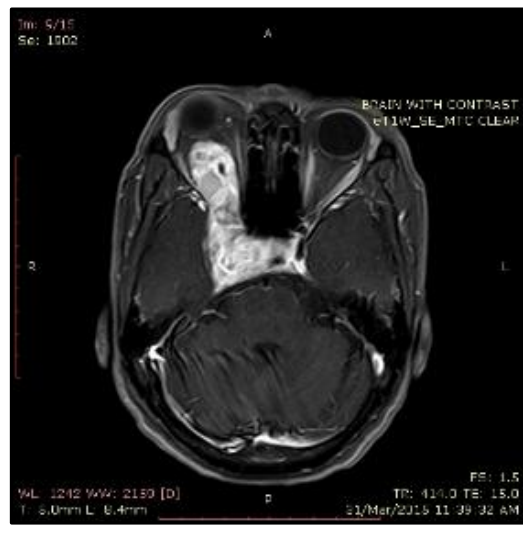

Fig. 5

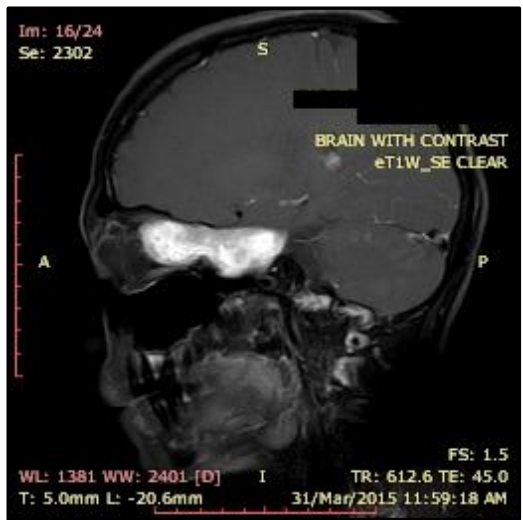

Fig. 6

\section{AUTHORS:}

1. Shruti S. Patil

2. Ananth

3. Atahar Sultana

\section{PARTICULARS OF CONTRIBUTORS:}

1. Associate Professor, Department of Radiology, M. R. Medical College, Gulbarga.

2. Post Graduate, Department of Radiology, M. R. Medical College, Gulbarga.

3. Post Graduate, Department of Radiology, M. R. Medical College, Gulbarga.

FINANCIAL OR OTHER COMPETING INTERESTS: None
NAME ADDRESS EMAIL ID OF THE CORRESPONDING AUTHOR:

Dr. Shruti S. Patil, House No. 203, 2nd Floor, Lahoti Apartment,

Opposite Goodluck Hotel, Khuba Plot, Gulbarga-585102, E-mail: drshrupatil@gmail.com

Date of Submission: 09/09/2015. Date of Peer Review: 10/09/2015. Date of Acceptance: 28/09/2015. Date of Publishing: 05/10/2015. 